\title{
Self-Efficacy Management Program on Physical Function of Knee Osteoarthritis among Elderly Patients at Assiut University Hospital.
}

\author{
Hanaa Moukhtar Ibrahim, Thanaa Mohammed Ahmed, Hesham Abd-El-Rahiem Elkady \& Safaa Ahmed \\ Kotp.
}

Assistant Lecturer of Geriatric Nursing Department, Faculty of nursing, Assiut University, Egypt.

Professor of Medical Surgical Nursing, Medical Surgical Nursing Department, Faculty of Nursing, Alexandria University, Egypt.

Professor of Orthopedic Surgery, Director of Arthroscopy and Sports Injuries Unit, Faculty of Medicine, Assiut University, Egypt.

Assistant professor of Community Health Nursing, Faculty of Nursing, Assiut University, Egypt.

\begin{abstract}
Osteoarthritis is common joint disease affecting older people, causes disability and reduced life quality. Aim determine effect of self-efficacy management program on achieve and improvements of pain and physical health. Subjects and method: Systemic random sample of 80 elders aged 60 yrs and old, divided into two equal groups (study and control). This study conducted from end of July 2012 to end of August 2013 at orthopedic outpatient clinics of Assiut University Hospital. Assessment conducted at the beginning, then after $8^{\text {th }}$ weeks and $6^{\text {th }}$ months from training, study tools included structure interview questionnaire, SF-36 questionnaire, pain rating scale, timed uplgo test and arthritis self-efficacy scale. Results: At posttest; $77.5 \%$ of study group had a poor physical health with not a statistically significant $(\mathrm{P}=0,785)$ and $55.0 \%$ of them had fair mental health with a statistically significant $(\mathrm{P}=0.043)$. Moreover, statistically significant difference $(\mathrm{P}<0.022)$ observed between pre and post test among study group regarding time uplgo test. Conclusion: Osteoarthritis knee program have a significant impact on elderly physical activity, However, post-test assessments of study group indicate that significant improvements regarding their self-efficacy. Recommendation: Osteoarthritis elders should participate in self-management programs and physical activity consistent with national guidelines.
\end{abstract}

\section{Key Words: Osteoarthritis, Self-Efficacy \& Elderly Physical Activity.}

\section{Introduction}

Knee osteoarthritis (OA) is the most common degenerative joint disorder in the elderly and a major public health problem throughout the world. It is the leading cause of pain and is estimated to be the fourth leading cause of disability among the aging population. It increases the risks of morbidity because loss of functional capacity, including difficulty in walking, inability to perform self-care, transferring, going up and down stairs, Knee OA not only impairs physical functions but also reduces quality of life. In addition, it is the third leading cause of life-years lost due to disability (March \& Bagga, 2004).

Osteoarthritis (OA) is a result of genetic, local mechanical stresses or systemic factors and is a chronic condition characterized by the breakdown and loss of the joint's cartilage, bony overgrowth and alterations in the ligaments, menisci and muscles around the joint. Cartilage is the part of the joint that cushions the ends of the bones and allows easy movement of joints. The breakdown of cartilage causes the bones to rub against each other. Symptoms of OA include joint pain, aching, stiffness and swelling resulting in decreased function and mobility (U.S.Department of Commerce., 2006).
World Health Organization reports that $80 \%$ of people with osteoarthritis have some degree of limitation, with $25 \%$ unable to carry out activities of daily life. The major consequences of osteoarthritis are: pain, stiffness, loss of joint mobility, disability, loss of independence, reduced social interaction, deformity and decline in well-being (WHO, 2003). Pharmacologic and surgical interventions are frequently applied in the knee OA treatment. These therapeutic strategies have yielded mixed success; however, are associated with adverse long term side effects. Sothat; current approaches to knee OA treatment have increasingly focused on identifying and developing more effective pain management strategies (Baker, et al., 2001).

Optimal osteoarthritis management involves both pharmacologic and behavioral intervention such as exercise and weight management (Zhang, et al., 2008). However, most osteoarthritis patients do not adequately practice these behavioral and most primary care practices are not set up to support them (Fontaine, et al., $2004 \&$ (CDC), 2005). So that, exercise is considered to be one of the most important treatments for patients with mild to moderate knee 
osteoarthritis It has Positive effects on pain and function, as well as cost-effectiveness has been reported (Altman, et al., 2000, Fransen, et al., 2003, Jordan, et al., 2003 \& Segal, et al., 2004).

\section{Aim of the study}

To determine the effect of self-efficacy management program on achieve and maintain clinically meaningful improvements in pain and physical function in elderly with knee osteoarthritis (OA). Also; To identify elderly osteoarthritis individuals who are at risk to fall.

\section{Research questions}

- Does osteoarthritis of knee program affect elderly physical and mental health?

- Does elderly osteoarthritis patients able to maintain long term physical activity?

\section{Subjects \& Method}

\section{Research Design \\ Quasi-Experimental design was used in the study. \\ Setting}

The study was carried out in orthopedic outpatients' clinics of main Assiut University Hospital.

\section{Subject}

Systemic random sample of 80 osteoarthritis elderly patients from both sexes" aged 60 years and more were included. Moreover the total numbers of patients were divided into two equal groups as the following; 40 patients for study group which attended osteoarthritis knee program sessions and other 40 patients for control group not included in program application and used for comparison.

Tools of data collection:- Five tools were utilized to collect data for this study, these are

Tool 1: A structured interview questionnaire was constructed by researcher after reviewing the relevant literature. To assess a comprehensive and accurate scocio-demographic characteristic of osteoarthritis patients. It includes personal data as name, age, address, sex, marital status, level of education and occupation....etc. "This tool was done only one time" Tool II: This tool included Short Form 36 Questionnaire (SF-36) to measures quality of life with only 36 questions which reflecting both physical and mental status and has 8 sub-components. Physical component which include Physical Function (PF), Role Physical (RP), Bodily Pain (BP) and General Health (GH) with (22) questions. While mental component consist of Mental Health (MH), Role Emotional (RE), Social Function (SF) and Vitality which represented by (14) questions (Brazier, et al., 1999 \& Ware, et al., 2002).

This tool was done three times for both study and control elders groups, the first time at the $1^{\text {st }}$ week before OAKP intervention, $2^{\text {nd }}$ time at $8^{\text {th }}$ week after application of OAKP and $3^{\text {rd }}$ time after $6^{\text {th }}$ months from application.

SF-36 questionnaire was translated into Arabic form and content validity of it was done by panel of seven experts from community health nursing, nursing administration, psychiatric nursing and medical nursing staff at Assiut University who reviewed the instrument for clarity, relevance, understanding, applicability and the necessary modification was done accordingly.

Tool III: Wong-Baker Faces Pain Rating Scale used in the present study to evaluate pain (severity. type, and duration), determine a treatment plan and evaluate the effectiveness of treatment (Hockenberry, et al., 2005).

This tool done three times for both study and control elders groups. The first time at the $1^{\text {st }}$ week before OAKP intervention, after that at $8^{\text {th }}$ week and at $6^{\text {th }}$ months after application of OAKP.

Tool IV: Timed Up \& Go Test (TUG):- It used in the present study to predict elderly osteoarthritis individuals who are at risk to falls. This test consist of steps followed to determine elderly quality of sitting, standing balance, safety during transfer through instruction of patient to get up and go at comfortable and safe pace to the line three meters, turn, return to the chair and sit down again ...etc. the test scored according to time taken to completed steps as the following [ $<14$ seconds: $87 \%$ not a high risk of falls and $\geq 14$ seconds: $87 \%$ a high risk of falls (Shumway, et al., 2000 \& Steffan, et al., 2002).

This tool was done three times for both study and control elders groups, the first time at the 1 st week before OAKP intervention, the second time at 8th week after application of OAKP and the third time after 6th months from application.

Tool V: This includes 8-item Arthritis Self-Efficacy Scale (ASES) is a self-administered, disease-specific questionnaire. This scale indicates the level of certainty that studied elderly can perform each task. Each question is scored on numeric rating scale ranging from $4=$ very uncertain, $5-6=$ moderately uncertain, and $10=$ very certain. Each subscale is scored separately by taking the mean score of the items. Higher scores indicate higher self-efficacy. This scale is available in (Lorig, et al., 1989 \& Lorig \& Holman, 1998).

This tool was done three times for both elders groups, the first time at the 1 st week before OAKP intervention, the second time at 8th week after application of OAKP and the third time after 6th months from application.

The Stanford Osteoarthritis of the Knee program (OAKP) 
The program has been developed by the researcher based on patients needs and review of relevant literature, available resources and revision by professor and assistant professor as well as expert in the field of orthopedic surgery, medical surgical nursing and community health nursing. According to the opinions of experts necessary modifications were made. It was delivered over a six-week period with studied elderly patients group attending one day of one and a half hours per week, after that; the researcher reassessed both study and control groups at eight week and after six months from starting.

\section{General objectives of the program}

Improvements of knee physical function and relieving pain.

\section{Specific objectives of the program}

- Teach the elders how to coping with osteoarthritis and measure used for joint protection,

- Motivate the elders toward modification of their behavior and practice about their disease.

- Decrease the risk of fall among elderly with knee osteoarthritis.

Assessment: Based on the results of pretest and reviewing the relevant literature about physical function and quality of life which denotes physical function deficit and reduced self efficacy; so the program media were prepared.

Planning stage: The arrangement of conducting the program done during this stage; the sessions and time of the program decided. The study group sample were attending one session of one and a half hours per week for six weeks period in a variety of numbers ranged between (1-3) in each day according to the date of first interview. Other facilities were checked and arranged during this phase as the teaching place and handout book ...etc.

Application Time: the time of application was decided according to the attendance of participants at orthopedic outpatients' clinics and the coordination between the researcher and elders patients.

Teaching place: - the program was conducted in the orthopedic outpatients' clinics.

Teaching methods and materials: It was important before implementing the program to prepare simple teaching methods; as discussion and role play. The media; as picture and handouts.

\section{Pilot study}

It was carried out before starting data collection on five (5) of osteoarthritis elderly patients attending orthopedic outpatient clinics at Assiut university Hospital. The aim of the pilot study is to test the clarity and applicability of the tools and determine the time required to fill the questionnaire. Based on the result of pilot study, the necessary modifications of tools were done.

\section{Implementation stage}

The knee osteoarthritis program was conducted in one year; which it was delivered over a six weeks with study elderly patients group attending one day per week, after that; the researcher reassessed both groups (study \&control) at eight week and after six months from starting.

Evaluation stage: the evaluation was done through:

A) Post test which done at 8th week after implementing and completing OAKP to assess elder's physical health and function.

B) Follow up which was done after 6th months of completing the osteoarthritis knee program.

The teaching program included organization of the program sequence.

Data collection phase

\section{Field work}

Before the application of the program, the patients were evaluated by assistant lecturer and senior resident of the orthopedic clinics to exclude diseases interfering with gait such as; cervical spondylosis, hip problems and other neurological disorder such as; parkinsonism. After that; the researcher introduced herself to participants to establish the necessary rapport, gain their attention and interest, an orientation to the program and its purpose was done and the elderly were informed about the time and place of session taken; Pretest was done before implementing the program to assess the elderly physical and mental health, each session started by a summary about what was given during the previous session and the objectives of the new topics. The post test at $8^{\text {th }}$ week and finally follow up test done after $6^{\text {th }}$ months for both groups were implemented by repeating the same format of the pre test to determine the effect of the program.

The educational program conducted in the period from end of July 2012 to end of August 2013.

\section{Ethical consideration}

The purpose and nature of this study was explained for directors of the studied settings. Also, every elderly have ethical rights to agree or refuse to participate in the study. An oral consent was taken from the elderly after informed them that the information obtained will be confidential and used only for the purpose of the study.

Statistical analysis

The data obtained were reviewed, prepared for computer entry, coded, analyzed and tabulated. Statistical analysis was done using the SPSS version $16 \& 19$. Descriptive statistics in the form of frequencies and percentages for qualitative variables. 
While means and standard deviations for quantitative variables. Chi-square, ANOVA test and T-test used to compare differences in the distribution of frequencies among different groups. Score range of Short Form 36 Questionnaire (SF-36) by summation of total items in physical and mental health which more than $50=$ fair health while less than $50=$ poor health It is considered significant when $\mathrm{P}$-values were less than $0.05(\mathrm{P}<0.05)$.

\section{Results}

Table (1): Distribution of the osteoarthritis elderly patients regarding to their socio demographic characteristics in outpatient clinics at Assiut university hospital (2013).

\begin{tabular}{|c|c|c|c|c|}
\hline \multirow{2}{*}{ Socio demographic characteristics } & \multicolumn{2}{|c|}{ study $(n=40)$} & \multicolumn{2}{|c|}{ Control $(n=40)$} \\
\hline & No. & $\%$ & No. & $\%$ \\
\hline \multicolumn{5}{|l|}{ Age } \\
\hline $60<65$ years & 19 & 47.5 & 13 & 32.5 \\
\hline $65<70$ years & 12 & 30.0 & 15 & 37.5 \\
\hline$\geq 70$ years & 9 & 22.5 & 12 & 30.0 \\
\hline Mean \pm SD & \multicolumn{2}{|c|}{$66.05 \pm 5.84$} & \multicolumn{2}{|c|}{$68.0 \pm 6.45$} \\
\hline \multicolumn{5}{|l|}{ Sex } \\
\hline Male & 26 & 65.0 & 15 & 37.5 \\
\hline Female & 14 & 35.0 & 25 & 62.5 \\
\hline \multicolumn{5}{|l|}{ Residence } \\
\hline Rural & 25 & 62.5 & 25 & 62.5 \\
\hline Urban & 15 & 37.5 & 15 & 37.5 \\
\hline \multicolumn{5}{|l|}{ Marital status } \\
\hline Married & 31 & 77.5 & 34 & 85.0 \\
\hline Widow & 9 & 22.5 & 6 & 15.0 \\
\hline \multicolumn{5}{|l|}{ Level of education } \\
\hline Illiterate & 27 & 67.5 & 35 & 87.5 \\
\hline Read \& write & 6 & 15.0 & 2 & 5.0 \\
\hline Primary & 1 & 2.5 & 0 & 0.0 \\
\hline Secondary & 3 & 7.5 & 2 & 5.0 \\
\hline University & 3 & 7.5 & 1 & 2.5 \\
\hline \multicolumn{5}{|l|}{ Occupation } \\
\hline Housewife & 14 & 35.5 & 24 & 60.0 \\
\hline Skilled worker & 4 & 10.0 & 1 & 2.5 \\
\hline Employee & 6 & 15.0 & 5 & 12.5 \\
\hline Free business & 2 & 5.0 & 3 & 7.5 \\
\hline Farmer & 9 & 22.5 & 4 & 10.0 \\
\hline Not working & 5 & 12.5 & 3 & 7.5 \\
\hline
\end{tabular}


Table (2): Distribution of osteoarthritis elderly patients regarding Physical health components according to SF-36 health survey throughout pre-test, post test and follow up in outpatient clinics at Assiut university hospital (2013).

\begin{tabular}{|c|c|c|c|c|c|c|c|c|c|}
\hline \multirow[t]{2}{*}{ Physical health level } & \multicolumn{2}{|c|}{$\begin{array}{c}\text { Pre } \\
(n=40)\end{array}$} & \multicolumn{2}{|c|}{$\begin{array}{c}\text { Post } \\
(n=40)\end{array}$} & \multicolumn{2}{|c|}{$\begin{array}{c}\text { Follow-up } \\
(n=40)\end{array}$} & \multirow[t]{2}{*}{ Test } & \multirow[t]{2}{*}{ P-value ${ }^{1}$} & \multirow[t]{2}{*}{ P-value ${ }^{2}$} \\
\hline & No. & $\%$ & No. & $\%$ & No. & $\%$ & & & \\
\hline \multicolumn{7}{|l|}{ Study group } & \multirow{6}{*}{$\begin{array}{c}\text { Chi- } \\
\text { Square } \\
\text { test. }\end{array}$} & \multirow{3}{*}{$0.785 \neq$} & \multirow{3}{*}{$1.000 \neq$} \\
\hline Poor level of physical health & 32 & 80.0 & 31 & 77.5 & 32 & 80.0 & & & \\
\hline Fair level of physical health & 8 & 20.0 & 9 & 22.5 & 8 & 20.0 & & & \\
\hline \multicolumn{7}{|l|}{ Control group } & & \multirow{3}{*}{$0.671 \neq$} & \multirow{3}{*}{$0.671 \neq$} \\
\hline Poor level of physical health & 36 & 90.0 & 38 & 95.0 & 38 & 95.0 & & & \\
\hline Fair level of physical health & 4 & 10.0 & 2 & 5.0 & 2 & 5.0 & & & \\
\hline
\end{tabular}

$\neq$ There are un-statistical significant differences at $P>0.05$.

$P$-value 1: between pre test and post test. $\quad$ P-value2: between pre test and follow-up test

Table (3): Distribution of osteoarthritis elderly patients in both group regarding mental health components according to SF-36 health survey throughout program phases (pre-post $8^{\text {th }}$ week - follow up when $6^{\text {th }}$ month) in outpatient clinics at Assiut university hospital (2013).

\begin{tabular}{|c|c|c|c|c|c|c|c|c|}
\hline \multirow{2}{*}{ Mental health levels } & \multicolumn{2}{|c|}{$\begin{array}{c}\text { Pre } \\
(n=40)\end{array}$} & \multicolumn{2}{|c|}{$\begin{array}{c}\text { Post } \\
(n=40)\end{array}$} & \multicolumn{2}{|c|}{$\begin{array}{c}\text { Follow-up } \\
(n=40)\end{array}$} & \multirow[t]{2}{*}{ P-value1 } & \multirow[t]{2}{*}{ P-value ${ }^{2}$} \\
\hline & No. & $\%$ & No. & $\%$ & No. & $\%$ & & \\
\hline \multicolumn{7}{|l|}{ Study group } & \multirow{3}{*}{$0.043 *$} & \multirow{3}{*}{1.000} \\
\hline $\begin{array}{l}\text { Poor level of mental } \\
\text { health }\end{array}$ & 27 & 67.5 & 18 & 45.0 & 27 & 67.5 & & \\
\hline $\begin{array}{l}\text { Fair level of mental } \\
\text { health }\end{array}$ & 13 & 32.5 & 22 & 55.0 & 13 & 32.5 & & \\
\hline \multicolumn{7}{|l|}{ Control group } & \multirow{3}{*}{1.000} & \multirow{3}{*}{0.775} \\
\hline $\begin{array}{l}\text { Poor level of mental } \\
\text { health }\end{array}$ & 32 & 80.0 & 32 & 80.0 & 33 & 82.5 & & \\
\hline $\begin{array}{l}\text { Fair level of mental } \\
\text { health }\end{array}$ & 8 & 20.0 & 8 & 20.0 & 7 & 17.5 & & \\
\hline
\end{tabular}

Chi-Square test was used, $\left(^{*}\right)$ There are statistical significant differences at $P<0.05, P$-valuel: between pre test and post test, P-value2: between pre test and follow-up test.

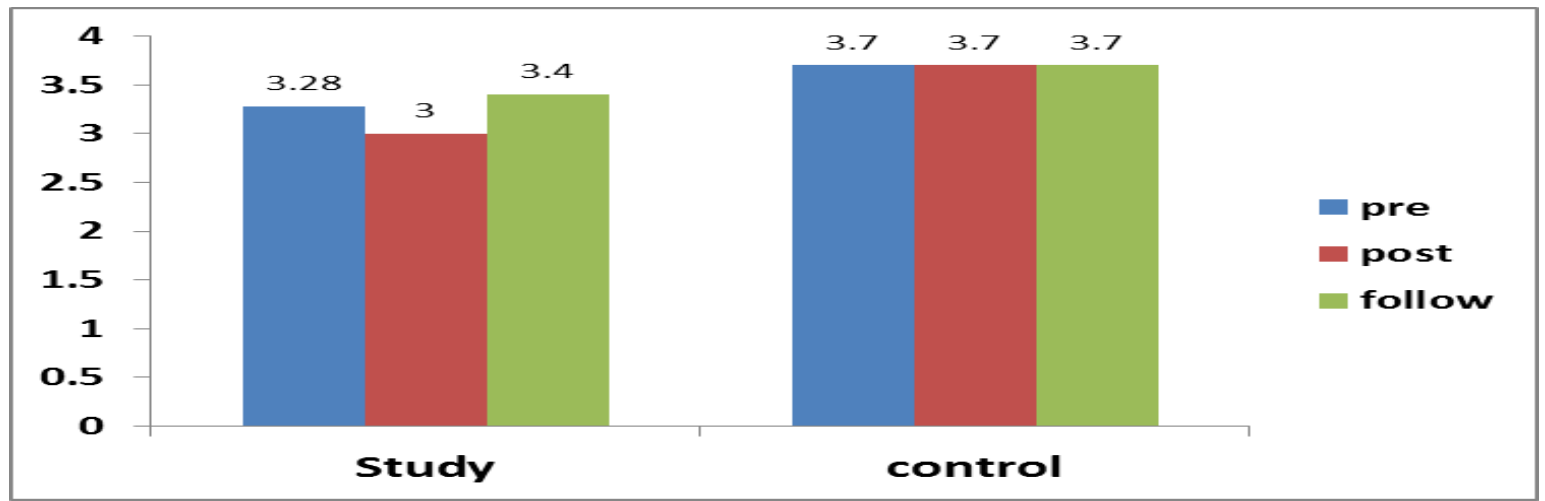

Paired samples t-test was used.

Figure (1): Impact of OAKP among both groups regarding Wong-Baker Faces Pain Rating Scale throughout program phases in outpatient clinics at Assiut university hospital (2013). 
Table (4): Impact of osteoarthritis knee program among both group regarding Time UP and Go test (TUG) at pre-test, post test and follow-up assessment in outpatient clinics at Assiut university hospital (2013).

\begin{tabular}{|c|c|c|c|c|c|c|c|c|c|}
\hline \multirow{2}{*}{ Time UP and Go test } & \multicolumn{2}{|c|}{$\begin{array}{c}\text { Pre } \\
(n=40)\end{array}$} & \multicolumn{2}{|c|}{$\begin{array}{c}\text { Post } \\
(n=40)\end{array}$} & \multicolumn{2}{|c|}{$\begin{array}{c}\text { Follow-up } \\
(n=40)\end{array}$} & \multirow{2}{*}{ Test } & \multirow{2}{*}{$\begin{array}{c}\text { P- } \\
\text { value }^{1}\end{array}$} & \multirow[t]{2}{*}{ P-value ${ }^{2}$} \\
\hline & No. & $\%$ & No. & $\%$ & No. & $\%$ & & & \\
\hline \multicolumn{7}{|l|}{ Study group } & \multirow{6}{*}{$\begin{array}{l}\text { Chi- } \\
\text { Square } \\
\text { test. }\end{array}$} & \multirow{3}{*}{$0.022 *$} & \multirow{3}{*}{$0.823 \neq$} \\
\hline Normal & 19 & 47.5 & 29 & 72.5 & 18 & 45.0 & & & \\
\hline Abnormal & 21 & 52.5 & 11 & 27.5 & 22 & 55.0 & & & \\
\hline \multicolumn{7}{|l|}{ Control group } & & \multirow{3}{*}{$0.919 \neq$} & \multirow{3}{*}{$0.469 \neq$} \\
\hline Normal & 14 & 35.0 & 15 & 37.5 & 11 & 27.5 & & & \\
\hline Abnormal & 26 & 65.0 & 25 & 62.5 & 29 & 72.5 & & & \\
\hline
\end{tabular}

$(*)$ significant at $P$-value $<0.05 . \quad \neq$ There are un-statistical significant differences $P$-valuel: between pre test and post test $\quad P$-value2: between pre test and follow-up test.

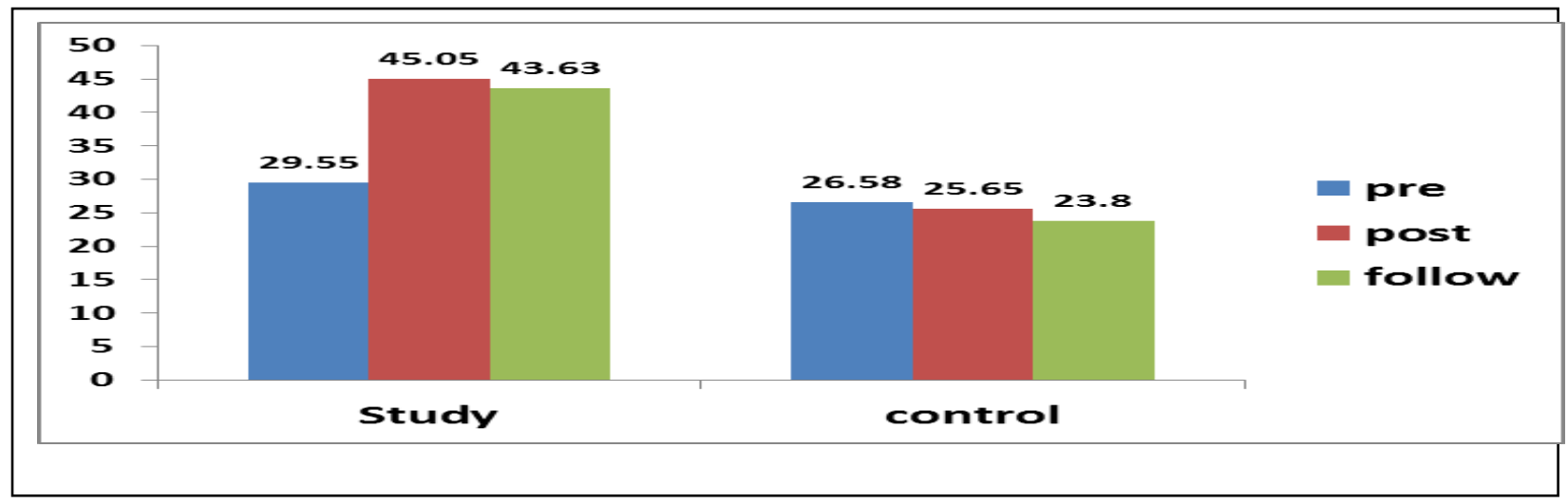

Paired samples t-test \& independent samples t-test was used.

Figure (2): Distribution of studies sample according to their Arthritis self-efficacy (ASE) score throughout three phases of program in outpatient clinics at Assiut university hospital (2013).

Table (5): Relation between age groups and total score of scales among study group sample during post-test assessment $\left(8^{\text {th }}\right.$ week) in outpatient clinics at Assiut university hospital (2013).

\begin{tabular}{|l|c|c|c|c|}
\hline \multirow{2}{*}{\multicolumn{1}{|c|}{ Total score of scales }} & \multicolumn{3}{|c|}{ Age (years) } & \multirow{2}{*}{ P-value } \\
\cline { 2 - 4 } & $\mathbf{<}$ & $\mathbf{6 5}-\mathbf{7 0}$ & $\geq \mathbf{7 0}$ & \\
\cline { 2 - 4 } & Mean \pm SD & Mean \pm SD & Mean \pm SD & \\
\hline Pain rating scale & $2.89 \pm 0.88$ & $2.83 \pm 1.03$ & $3.44 \pm 1.24$ & $0.331 \neq$ \\
\hline Time up and go test & $11.53 \pm 2.65$ & $10.42 \pm 5.00$ & $13.11 \pm 2.93$ & $0.243 \neq$ \\
\hline Arthritis self-efficacy scale & $48.05 \pm 19.09$ & $45.67 \pm 9.53$ & $37.89 \pm 19.92$ & $0.344 \neq$ \\
\hline
\end{tabular}

$\neq P$-value is un-statistically significant difference at $>0.05$. (ANOVA Test).

Table (6): Relation between age groups and total score of scales among study group during Follow-up assessment in outpatient clinics at Assiut university hospital (2013).

\begin{tabular}{|l|c|c|c|c|}
\hline \multirow{2}{*}{\multicolumn{1}{c|}{ Total score of scales }} & \multicolumn{3}{|c|}{ Age } & \multirow{2}{*}{ P-value } \\
\cline { 2 - 4 } & $\mathbf{< 6 5}$ & $\mathbf{6 5}-\mathbf{6 7 0}$ & $\geq \mathbf{7 0}$ & \\
\cline { 2 - 4 } & Mean \pm SD & Mean \pm SD & Mean \pm SD & \\
\hline Pain rating scale & $3.26 \pm 1.05$ & $3.58 \pm 1.17$ & $3.44 \pm 1.24$ & $0.738 \neq$ \\
\hline Time up and go test & $13.26 \pm 3.46$ & $12.08 \pm 4.14$ & $14.67 \pm 3.32$ & $0.287 \neq$ \\
\hline Arthritis self-efficacy scale & $47.42 \pm 23.25$ & $41.92 \pm 12.76$ & $37.89 \pm 19.92$ & $0.474 \neq$ \\
\hline
\end{tabular}

$\neq P$-value is un-statistically significant difference at $>0.05$. (ANOVA Test). 
Table (1): shows that distribution of osteoarthritis elderly patients regarding to their socio demographic characteristics, that nearly half $(47.5 \%)$ of the study group their age ranged between $60<65$ years, while more than one third (37.5\%) of control group aged 65 $-<70$ years. Concerning to their sex, it was found that about two-third (65\%) of the study group were male and $62.5 \%$ of control group were female. As regard the residence of studied sample, $62.5 \%$ of both groups were comes from rural areas. The table also shows that $77.5 \%$ and $22.5 \%$ were married and widow from study group, respectively, while the majority $(85.0 \%)$ of control group were married. Concerning educational level of the studied elderly, it was found that $67.5 \%$ and $87.5 \%$ were illiterate from both study and control groups, respectively. Only $7.5 \% \mathrm{o}$ and $2.5 \%$ accomplished University education from both study and control group, respectively.

Regarding to the occupational status, it was clear that all female gender in both study and control group were housewife, While more than one fifth $(22.5 \%)$ of study group and only $10.0 \%$ of the control group of male were farmer. Concerning to floor which studied sample were living, the majority $(72.5 \%$ and $85.0 \%$ ) of both study and control group were living at ground floor.

Table (2): The table reveals that there is minimal change between pre-test $(80.0 \%)$ and post test (77.5\%) of study elders group had a poor level of physical health. These differences were not a statistically significant (P-value $1<0.785)$. However, the majority $(90.0 \%$ and $95.0 \%)$ of control elderly had a poor level of physical health at pre-test and post test, respectively. The differences between both assessments are not statistically significant ( $\mathrm{p}$-value 1 $<0.671)$.

According to distribution of the studied sample regarding their total level of mental health Components by using (SF-36) health scale.

Table (3): indicates that slightly more than two-third $(67.5 \%)$ of study group in the first week of data collection (pre-test) had a poor level of mental health. While more than half $(55.0 \%)$ of them had fair level of mental health in post test $8^{\text {th }}$ week. These findings indicate that there is a significant difference between pretest and post test at ( $\mathrm{p}$-value $\left.{ }^{1}<0.043\right)$. While; among the control group observed that equal percentage $(80.0 \%)$ in pre-test and post test had a poor level of mental health with not a statistically significant difference ( $\mathrm{p}$-value ${ }^{1}<1.000$ ).

Figure (l): illustrated the impact of OAKP among both groups regarding Wong-Baker Faces Pain Rating Scale throughout program phases. It was found that there was no statistical significant difference among both study and control groups throughout of program phases regarding pain rating (p-value >0.05).

Table (4): Display the distribution of studied sample by normal and abnormal time/seconds required to complete (TUG) test based on their age. It appears from the table that, $(47.5 \%)$ of study group in pre-test and $(72.5 \%)$ from them in post test were complete test within normal range of time/seconds. These differences between pre and post test are statistically significant $\left(p\right.$-value $\left.{ }^{1}>0.022\right)$. While among control group the differences between each assessment phase (pre, post and follow-up assessment) not statistical significant was observed $\left(\mathrm{P}\right.$-value ${ }^{1}<0.919$ and Pvalue $\left.^{2}<0.469\right)$ respectively.

Figure (2): display the distribution of studies sample according to their Arthritis Self-Efficacy (ASE) score throughout phases of program, it was observed that there was highly statistical significant difference among study group regarding Arthritis self--efficacy Scale throughout program phases $\left(\mathrm{P}\right.$-value ${ }^{1}<0.003$ and $\mathrm{P}$-value $\left.{ }^{2}<0.000\right)$. Meanwhile no statistical differences detected throughout OAKP phases among control group ( $\mathrm{P}$-value ${ }^{1}<0.181$ and $\left.\mathrm{Pvalue}^{2}<0.354\right)$. Also as regarding to relation between study and control group according to arthritis self-efficacy scale, the result reveal that highly statistical significant difference at post test $\left(8^{\text {th }}\right.$ weeks $)$ and follow-up $\left(6^{\text {th }}\right.$ months $)$ (P-value $\left.<0.000\right)$.

Table (5): This displays the relation between age groups with total score of Pain rating scale, time upl go test and arthritis self-efficacy scale among study group sample during post-test assessment. It clear that there are no statistically significant differences in relation of total score with their age of study group (P-value; <0.331, <0.243, <0.244) respectively.

Table (6): illustrated that there is no statistically significant difference in relation of total score of pain rating scale, time uplgo test and arthritis self-efficacy scale with their age of study group at follow-up assessment phase of program (P-value; < 0.738, $<0.287,<0.474)$ respectively.

\section{Discussion}

Osteoarthritis is the most common joint disease worldwide (Michael, et al., 2010) that appears to originate in the cartilage and affects the underlying bone, soft tissues and synovial fluid. It is mostly affecting the hand and large weight-bearing joints such as the knee (Flugsrud, et al., 2010). The evidence supports the use of self-management programs in primary care of patients with knee osteoarthritis; it was conducted by various healthcare providers including rheumatologists, nurses, physical and occupational therapists and health educators. 
This was modified to include an exercise component (Coleman, et al., 2012).

Concerning socio-demographic characteristics of the sample, two groups (study and control) were included in this study with no a statistical significant difference found between them regarding age. All elders participated in this study their age ranged from sixty to eighty-four years. This means that the young older adults is the age of beginning of knee osteoarthritis and reflect the serious effect of age and age related changes on health status among elderly people.

Moreover, the current study agree with the same result of study conducted in Cairo by Ahmed, (2011) about effect of sensorimotor training on balance in elderly patients with knee osteoarthritis and reported that there were no significant differences between the groups with respect to age. In addition to the current findings in accords with the findings of the study conducted in America by Maly, et al., (2005) who reported that the same mean age of his studied sample and ranged fifty to eighty-nine years. The above findings are confronted with the published results of the study conducted in Saudi Arabia by Alrushud, et al., (2013) about impact of knee osteoarthritis on the quality of life among Saudi elders, who reported that their sample aged between sixty to seventy years.

This study revealed that the total number of male higher than female in study group. However limitations should be noted when interpreting the previous findings. Such as, the participants of this study included a greater proportion of men than those originally interviewed to participate. However, many of female patients come only to take medication and believe that their age, sex and more physically active lifestyle pattern are risk factor of disease. These results disagree with that reported by study conducted in New York by Marks, (2013), that higher percentage of sample was female.

This results is contradicted with Coleman, et al., (2012) who implemented their study at randomized controlled trail of a self-management education program for osteoarthritis of the knee delivered by health care professionals, they found that the majority of sample were female with the following male to female ratio; (23:52 in control and 14:57 in OAK). Also our finding is contradicted with study conducted by Cho, et al., (2011) about gender and prevalence of knee osteoarthritis types in elderly Koreans which reported that men had lower prevalence than women for radiographic and severe radiographic osteoarthritis and with the findings of the study conducted in Tokyo by Muraki, et al., (2010) who reported that the female sex was strong risk factor even in the subgroup without radiographic knee osteoarthritis.

Furthermore, in study conducted by Zhang, et al., (2001), who found that the prevalence of OA increased with age in both men and women. In their population; women showed a similar increasing pattern; but in men a steep increase in prevalence was observed between sixty-five to sixty-nine years old and seventy to seventy-four years old subject and no significant increase was observed subsequently. This finding might be interpreted to mean that aging does not increase the risk of knee OA development.

As regard to residence of elderly sample the finding of current study found that about two-third of both groups came from rural area. This may be related to unawareness/negligence of rural families toward general health care, protection of joints, effect of excessive joint use, extreme daily activities and not accessibility of health care services in rural areas. A similar finding also was presented in the study conducted in Tokyo by Muraki, et al., (2010) which documented that rural residency were risk factors for radiographic knee $\mathrm{OA}$, knee pain and their combination.

Based on studied sample occupation, The present findings indicated that more than one-third in study group and two-third in control group were housewife, while farmer were observed in one third among male studied subjects. This finding could be attributed to excessive joint use in stair climbing, bending, lack of physical activity performance and lack of knowledge about joint protection which in turn lead to increase the risk for development of knee osteoarthritis.

The SF-36 encompasses eight domains of healthrelated quality of life and has been widely used in OA populations (Kosinski, et al., 1999). Domain of role limitations due to physical health was markedly affected by the disease, this domain were collected by asked elderly about physical function, role physical, bodily pain and general health while role limitation due to emotional problems includes four items related to the psychological health. Participants were asked about the effect of their psychological state on their mental health, role emotional, vitality and social activity time and quality.

Results of the current study showed a negative impact of knee OA on quality of life (QOL) of studied elders. Which, all domains of SF-36 of patients with knee OA are affected by the disease as they had lower scores for both physical and mental health components of the SF-36 questionnaire, while, a significant difference improvement was observed in mental health for study group at post test phase following application of program. However; these improvements were declined at follow-up. This may be due to unawareness of elderly people who have 
knee osteoarthritis for importance of follow-up care and the effect of age-related changes on their general health.

Similar findings are found in the study carried out by Alrushud, et al., (2013) who reported that a significant negative impact of knee osteoarthritis on quality of life of Saudi elders compared with elders without knee osteoarthritis. All domains of SF-36 of patients with knee $\mathrm{OA}$ are affected by the disease as they had lower scores than elders without knee OA. Moreover, they had lower scores for both physical and mental components sof the SF-36 questionnaire with highly statistically significant for both.

Also, this finding is consistent with other research studies conducted in different countries such as Cook, et al., (2007) in the U.S., who found that elders with knee OA are more likely to report lower levels of quality of life (QOL) even with controlling the confounding variables of age, gender, race, education and income. Zakaria, et al., (2009) in Malaysia, who measured the elder's patient QOL by using SF-36 and stated that patients with knee OA attending primary care clinics have relatively poor QOL.

In addition to, Chacon, et al., (2004) in Venezuela, had measured QOL using the arthritis impact measurement scales in a version translated to Spanish, and they found that the perception of QOL is negatively affected by increasing the level of joint pain, old age and low socioeconomic status in elderly patients with knee OA. Yildiz, et al., (2009) in Nottingham, concluded that elderly patients with knee osteoarthritis undergo a significant impact on multiple dimensions of QOL compared with healthy controls.

Another study was done by Muaraki, et al., (2010) in Japan, who found that knee OA was significantly associated with lower QOL scores among the elder women. Boonsin, (2006). In Thailand, stated that knee OA has a negative impact on QOL. Salafi, et al., (2005) in Italy, stated that elderly patients with knee OA had significant lower scores of SF-36. However, these findings stand in opposition to the results of Dominick, et al., (2005) who compared QOL responses among elder's subjects with OA, rheumatoid arthritis and no arthritis diagnosis mentioned that there is no statistically significant differences in QOL scores between subjects with osteoarthritis and those without arthritis.

Depending on results of the current study found that the responsiveness of the mental health component of SF-36 is relatively high than physical health component throughout program phase among study group of elderly, while lack of response in both mental and physical health component was observed among control group. This could be referred to two reasons. Firstly, that knee OA causes pain and disability, leading to increase elderly dependant in performing daily living activities and prevents them from having a normal life. Secondly, it may be referred to poor adaptation to this chronic disease.

Moreover, the finding of the present study in accordance with the result conducted by Muraki, et al., (2010) who measured QOL among elders with knee osteoarthritis, found that subjects with symptomatic knee $\mathrm{OA}$ had significantly lower physical QOL.

Also, the finding of Jinks, et al., (2007) is inconsistence with the current study results; noticed that the major change in self-reported health status between baseline and follow-up was the decline in physical function among persons who developed knee pain. Although there was evidence that this group already had slightly poorer physical health status at baseline' On the other hand, Zakaria, et al., (2009) in their study to measure the QOL among patients with symptomatic knee OA, found that the physical health showed better score compared with mental health.

These results are confronted with the results of the study conducted by Alrushud, et al, (2013), who reported that the responsiveness of the mental health component of SF-36 is relatively low when compared with the physical health component. Also, the higher scores in the mental health component compared with the physical component were disagreeing with other studies. Cook, et al., (2007) found that individuals with $\mathrm{OA}$ are more likely to report mental health problems. While, Tangtrakulwanice, et al., (2006) proved that responsiveness of the mental health component of SF-36 is relatively low when compared with the physical component.

Pain was considered as a major determinant loss of function in individuals with OA. They limit their functional activities to avoid movements that exacerbate pain during performing activities of daily living (Loyland, et al., 2010). In the current study findings, the study group demonstrated mild improvement in severity of pain throughout program phases but with no a statistical difference among both study and control group. On the other hand, these findings are contrasted with Coleman, et al., (2012) who mentioned that pain decreased about one third during the post-test intervention in OAK group and the control group had increase in pain level during the same phase with a statistical difference for both groups.

In this context, Ahmed, (2014) reported that the least visual analogue scale (VAS) score among women with unilateral left knee involvement was (57.5), with considered the score of $<40 \mathrm{~mm}$ at rest and $<50 \mathrm{~mm}$ on movement as the acceptable symptomatic state in 
patients with lower limb OA, Furthermore, this finding also disagree with another studies conducted by Ahmed, (2011) which documented that the study group showed more signiflrcant reduction of pain than the control group.

The current study displayed that improvement of elders' basic functional mobility in the study group according to time-up and go (TUG) test with a significant difference between pre and post intervention of program compared to control group. This findings supported by Van, et al., (2008) who mentioned that the TUG test results showed a significant improvement in the OAK group compared with the control group at post intervention and follow-up.

Also; study of Coleman, et al., (2012) added that the TUG test improved during the period between baseline and sixth month in the OAK group compared with the control group' although these improvements had little clinical relevance.

Regarding self-efficacy, this study demonstrated improvement in the confidence that studied elderly abilities to perform a specific task with a significant difference was observed at post intervention and follow-up among study group compared to control group, Moreover' the current findings revealed a statistical difference between study and control group during post intervention and follow-up phases of program. A similar finding also was presented in the study conducted in Denmark by Gains, et al., (2002) which documented that a significant relationship between the functional self efficacy (FSE) and selfreported performance in twenty women with knee OA. No significant relationship was found in the men, who participated.

Moreover; the current study agree with the results of study conducted by Sharma, et al., (2003) \& Harrison, (2004) reported that high levels of selfefficacy resulted in decreased odds of poor observed performance of a sit-to-stand task over the span of three years in people with knee osteoarthritis. On the other hand; the previous results are supported with the published results conducted by Maly, et al., (2005) who mentioned that the self-efficacy scores in these other studies are much lower (indicating poorer levels of self-efficacy) than those obtained in their sample.

Unfortunately, the present findings indicated that most of studied elders within age group sixty to less than or equal sixty-five years are not suffering from others chronic disease and doing physical exercise demonstrate improvement in their self-efficacy, timeuplgo test and severity of pain at post test assessment and this improvements slightly decrease at sixth months follow-up assessments. This means that the young older adults is the age of beginning of health problems and reflect the serious effect of age and age related changes on health and cognitive function among elderly people. So that, early enhancing selfefficacy has become an essential feature of most arthritis management because of its relationships with health behaviors and health status.

\section{Conclusion}

Based on the findings of the current study. It can be concluded that the osteoarthritis of knee program (OAKP) have a significant impact on the physical activity of elderly patients. However, assessments of the study group at post test $\left(8^{\text {th }}\right.$ weeks) phase of program after exercise interventions indicate that the significant improvements regarding arthritis selfefficacy scale. While these improvements slightly decrease at $6^{\text {th }}$ months follow-up assessments.

\section{Recommendations}

Based on the study results, the following recommendations are suggested implementation of self management education (SME) should be expanded as a community based intervention with supportive tools, evaluation and strategies for promoting the maintenance of long-term exercise. Further other program applied about knee osteoarthritis for elderly caregiver is very important health issues to ensure the continuity of care and perform of physical activity exercise.

\section{References}

1. Ahmed A., (2014): Relationship between the radiological grading and both functional performance and health related quality of life among women with knee osteoarthritis, Damanhour.

2. Ahmed F., (2011): Effect of sensorimotor training on balance in elderly patients with knee osteoarthritis, Cairo

3. Alrushud S., El-Sobkey S., Hafez A., \& AlAhaideb A., (2013): Impact of knee osteoarthritis on the quality of life among Saudi elders: A comparative study Riyadh, Saudi Arabia.

4. Altman R., Hochberg M., Moskowitz R., \& Schnitzer T., (2000): Recommendations for the medical management of osteoarthritis of the hip and knee: 2000 update. American College of Rheumatology Subcommittee on Osteoarthritis Guidelines. Arthritis Rheum. 43:1905-1915. doi: 10.1002/1529-0131(200009)43:9<1905::AIDANR1>3.0.CO;2-P.

5. Baker K., Nelson M., Felson D., Layne J., Sarno R., \& Roubenoff R., (2001): the efficacy 
of home based progressive strength training in older adults with knee osteoarthritis: A randomized controlled trial. Journal of Rheumatology. 18, 1655-1665.

6. Boonsin T., (2006): Comparing quality of life among people with different patterns and severities of knee osteoarthritis. Musculoskeletal Res; 10:47-55.

7. Brazier J., Harper R., Munro J., Walters S., \& Snaith M., (1999): Generic and conditionspecific outcome measures for people with osteoarthritis of the knee. Rheumatology (Oxford);3 8 (9): 870-877. doi: I 0. 1093/rheumatology/3 8.9.870.

8. Centers for Disease Control \& Prevention (CDC), (2005): Monitoring progress in arthritis management-United States and 25 states. MMWR Morb Mortal Wkly Rep.54:484-8.

9. Chacón J., González N., Véliz A., Losada B., \& et al., (2004): Effect of knee osteoarthritis on the perception of quality of life in Venezuelan patients. Arthritis Rheum; 51:377-82.

10. Cho H., Chang C., Kim K., \& et al., (2011): Gender and prevalence of knee osteoarthritis types in elderly Koreans. J Arthroplasty; 26(7): 994-999.

11. Coleman S., Briffa N., Carroll2 G., Inderjeeth C., \& et al., (2012): Arthritis Research \& Therapy "A randomised controlled trial of a self management education program for osteoarthritis of the knee delivered by health care professionals", 14:R21 http://arthritisresearch.com/content/14/1/R21 Page 12 of 14

12. Cook C., Pietrobon R., \& Hegedus E., (2007): Osteoarthritis and the impact on quality of life health indicators. Rheumatol Int; 27:315-21.

13. Dominick K., Jordan J., Renner J., \& Kraus V., (2005): Relationship of radiographic and clinical variables to pinch and grip strength among individuals with osteoarthritis. Arthritis Rheum. 52(5):1424-30.

14. Flugsrud G., Nordsletten L., Reinholt F., Risberg M., \& et al., (2010): Osteoarthritis. Tidsskr. Nor. Laegeforen. 130: 2136-2140

15. Fontaine K., Heo M., \& Bathon J., (2004): Are US adults with arthritis meeting public health recommendations for physical activity? Arthritis Rheum. 50:624-8.

16. Gaines J., Talbot L., \& Metter E., (2002): the relationship of arthritis self efficacy to functional performance in older men and women with osteoarthritis of the knee. Geriatric Nursing; 23:167-170.

17. Harrison L., (2004): The Influence of Pathology, Pain, Balance and Self-efficacy on Function in Women with Osteoarthritis of the
Knee, Journal of the American Physical therapy Association ; 8 :822-831.

18. Hockenberry M., Wilson D., \& Winkelstein M., (2005): Wong's Essentials of Pediatric Nursing, ed. 7, St. Louis, p.1259. Used with permission. Copyright, Mosby.

19. Jinks C., Jordan. K., \& Croft P., (2007): Osteoarthritis as a public health problem: the impact of developing knee pain on physical function in adults living in the community:Keele, Staffordshire ST5 5BG, UK. E-mail: c.jinks@cphc.keele.ac.uk

20. Jordan K., Arden N., Doherty M., Bannwarth B., \& et al., (2003): EULAR recommendations: An evidence based approach to the management of knee osteoarthritis: report of a task force of the Standing Committee for International Clinlcal Studies Including Therapeutic Trials. Annals of the Rheumatic Diseases. 62 (12): 1145-55.

21. Kosinski M., Keller S., Hatoum H., Kong S., \& et al., (1999): The SF-36 Health Survey as a generic outcome measure in clinical trials of patients with osteoarthritis and rheumatoid arthritis: Tests of data quality, scaling assumptions and score reliability. Med Care; 37:MS10-22.

22. Lorig K., \& Holman H., (1998): Arthritis selfefficacy scales measure self-efficacy. Arthritis Care and Research, 11,155-157.

23. Lorig K., Brown B., Ung E., Chastain R., \& et al., (1989): Development and evaluation of a scale to measure the perceived self-efficacy of people with arthritis. Arthritis and Rheumatism, 32(1), pp.37 -44.

24. Løyland B., Miaskowski C., Paul S., \& et al., (2010): The relationship between chronic pain and health-related quality of life in long-term social assistance recipients in Norway. Qual Life Res; 19:1457-65.

25. Maly R., Costigan A., \& Olney J., (2005): Contribution of psychosocial and Mechanical Variables to physical performance measure in knee osteoarthritis.

26. March L., \& Bagga H., (2004): Epidemiology of osteoarthritis in Australia. Med J Ausr.; 180 (Suppl 5):S6-S10.

27. Marks R., (2013): Depressive Symptoms among Community-Dwelling Older Adults with Mild to Moderate Knee Osteoarthritis: Extent, Interrelationships, and Predictors, New York, American Journal of Medicine Studies 1, no. 3 (2013): 11-18. doi: 10.12691/ajms-1-3-1.

28. Michael J., Schlüter-Brust K., \& Eysel P., (2010): The epidemiology, etiology, diagnosis, 
and treatment of osteoarthritis of the knee. Dtsch. Arztebl. Int. 107: 152-162.

29. Muraki S., Akune T., Oka H., En-yo T., \& Yosshida M., (2010): Impact of knee and low back pain on health related quality of life in Japanese women: The research on osteoarthritis against disability (ROAD). Mod Rheumatol; 20:444-51.

30. Sallafi F., Carotti M., \& Grassi W., (2005): Health related quality of life in patients with hip or knee oasteoarthritis: Comparison of generic and disease-specific instruments. Clin Rheumatol; 24:29-37.

31. Segal L., Day S., Chapman A., \& Osborne R., (2004): Can we reduce disease burden from osteoarthritis? Med J Aust. 2004; 180:S11-7.

32. Sharma L., Cahue S., Song J., \& et al., (2003): Physical functioning over three years in knee osteoarthritis: role of psychosocial, local mechanical, and neuromuscular factors. Arthritis Rheum. 48:3359-3370.

33. Shumway-C., Brauer S., \& Woollacott M., (2000): Predicting the probability for falls in community-dwelling older adults using the Timed Up \& Go Test. Phys Ther. 80(9):896-903.

34. Steffan T., Hacker T., \& Mollinger L., (2002): Age- and gender-related test performance in community dwelling elderly people: six-minute walk test, Berg balance scale, Timed up \& Go Test, and gait speeds. Phys Ther. 82:128-137.

35. Tangtrakulwanich B., Wiwatwongwana S., Chongsuvivatwong V., \& Geater A., (2006): Comparison of validity, and responsiveness between general and disease-specific quality of life instruments in knee osteoarthritis. J Med Assoc (Thai version); 89:1454-9.

36. U.S. Department of Commerce, (2006); Facts for Features - January 3(2006), http://www.census.gov.

37. Van I M., Munneke M., Esselink R., Benraad C., \& Olde Rikkert M., (2008): Gait Velocity and the Timed-up and Go test were sensitive to changes in mobility in frail elderly patients. Journal of Clinical Epidemiology, 61(2):186191.

38. Ware J., Kosinski M., Turner-Bowker D., \& Gandek B., (2002): How to Score Version 2 of he SF-12® Health Survey (With a Supplement Documenting Version 1). Lincoln, RI: QualityMetric Incorporated.

39. World Health Organisation (WHO), (2003): http://www.boneandjointdecade.org/default2.html.

40. Yildiz N., Topuz O., Gungen G., Deniz S., \& et al., (2009): Health-related quality of life (Nottingham Health ProWle) in knee osteoarthritis: correlation with clinical variables and self-reported disability. Rheumatol Int; 10:296-301.

41. Zakaria Z., Bakar A., Hasmoni H., Rani F., \& Kadir S., (2009): Health-related quality of life in patients with knee osteoarthritis attending two primary care clinics in Malaysia: A crosssectional study. Asia Pac Fam Med; 8:1.

42. Zhang W., Moskowitz R., Nuki G., Abramson S., Altman R., Arden N., \& et al., (2008): OARSI recommendations for the management of hip and knee osteoarthritis, Part II: OARSI evidence-based, expert consensus guidelines. Osteoarthritis Cartilage;16:137-62.

43. Zhang Y., Xu L., Nevitt M., \& et al., (2001): Comparison of the prevalence of knee osteoarthritis between the elderly Chinese population in Beijing and whites in the United States: The Beijing Osteoarthritis Study. Arthritis Rheum. 44(9):2065-71. 